Article

\title{
Hybrid LLC Converter with Wide Range of Zero-Voltage Switching and Wide Input Voltage Operation
}

\author{
Bor-Ren Lin * and Kun-Yi Chen \\ Department of Electrical Engineering, National Yunlin University of Science and Technology, Yunlin 640, Taiwan; \\ m10812010@yuntech.edu.tw \\ * Correspondence: linbr@yuntech.edu.tw
}

Received: 26 October 2020; Accepted: 18 November 2020; Published: 20 November 2020

\begin{abstract}
A new hybrid inductor-inductor-capacitor (LLC) converter is investigated to have wide voltage input operation capability and zero-voltage turn-on characteristics. The presented circuit topology can be applied for consumer power units without power factor correction or with long hold-up time requirement, photovoltaic energy conversion and renewable energy power transfer. To overcome the weakness of narrow voltage gain of resonant converter, the hybrid LLC converter with different turns ratio of transformer is presented and the experimental investigation is provided to achieve wide voltage input capability ( $400 \mathrm{~V}-50 \mathrm{~V})$. On the input-side, the converter can operate as full bridge resonant circuit or half bridge resonant circuit with input split capacitors for high or low voltage input region. On the output-side, the less or more winding turns is selected to overcome wide voltage input operation. According to the circuit structures and transformer turns ratio, the single stage LLC converter with wide voltage input operation capability ( $400 \mathrm{~V}-50 \mathrm{~V})$ is accomplished. The laboratory prototype has been developed and the experimental waveforms are measured and demonstrated to investigate the effectiveness of the presented hybrid LLC converter.
\end{abstract}

Keywords: hybrid LLC converter; wide voltage input; zero-voltage switching; dc-dc converters

\section{Introduction}

The renewable energy systems have been presented and established to reduce fossil fuel demand and prevent the influence of global warming. The output of renewable energy sources may be unstable voltage or current with dc or ac waveform. Power electronics play the principle of energy transfer between renewable energy sources and energy storage elements or loads. The output of photovoltaic (PV) panel or small-scale wind turbine generator is an unstable and non-constant dc voltage. Therefore, dc converters with wide voltage input capability are normally demanded to achieve the principle of energy transfer between PV panel (or small-scale wind generator) and energy storage unit or dc load. The power switches of dc-dc converters can be controlled by pulse-width modulation (PWM) [1-3] or frequency modulation (FM) [4-6]. In PWM control, the switching frequency is fixed but duty cycle is variable in order to control load voltage. In FM control, the duty cycle is fixed and the switching frequency is variable to control voltage transfer function of dc converters and regulate load voltage. Gallium Nitride (GaN) FET, Insulated Gate Bipolar Transistors (IGBTs), Metal-Oxide-Semiconductor Field-Effect Transistor (MOSFET) and Silicon Carbide ( $\mathrm{SiC}$ ) devices are widely used in power electronics. The main drawback of IGBT devices is low frequency operation. SiC and GaN devices have advantages of high frequency operation and low switching loss for high power density applications. However, $\mathrm{SiC}$ and $\mathrm{GaN}$ devices have high cost problem compared to MOSFET and IGBT devices. In medium power applications, MOSFET devices have advantages of low cost and medium frequency operation capability. 
High frequency and high efficiency power converters are demanded to achieve energy transfer from renewable energy sources to the energy storage units. Due to wide voltage variation of the solar panel output or low power wind generator, the soft switching converters with wide voltage input or output operation have studied. The series-connected dc-dc converter has studied in Reference [7] to accomplish wide input voltage operation for power conversion and battery charger applications. The disadvantage of the series-connected dc-dc converter is poor efficiency. The series/parallel-connected converters with wide voltage operation for vehicles were presented in References [8-11]. The circuit topology needs more active and passive components so that the efficiency and reliability are decreased. Phase-shift PWM scheme with a wide voltage input/output operation were studied in References [12-14]. The main problems of these topologies are the complicated control algorithm, high freewheeling current and hard switching operation at low load condition. Interleaved converters with frequency control have been presented in Reference [15] to have low input ripple current and achieve wide voltage input. This circuit topology is still a multistage circuit. The inductor-inductor-capacitor (LLC) converter with different winding turns was reported in Reference [16] to increase hold-up time on power units of personal computer applications. Four secondary windings are needed so that the conduction loss is increased on the transformer windings. In conventional LLC converter, the circuit can operate well at the limit voltage range to achieve low freewheeling current loss and high circuit efficiency. If the wide voltage range operation is demanded, the low inductor ratio between the magnetizing inductor and resonant inductor and low quality factor are needed in conventional LLC converter to achieve high voltage gain. However, the magnetizing inductance is decreased and the circulating current loss is increased. Therefore, the LLC converter efficiency is decreased. To solve this problem, a hybrid LLC circuit operation [17] shown in Figure 1a has been proposed to realize 4:1 wide voltage operation $\left(\mathrm{V}_{\max }=4 \mathrm{~V}_{\min }\right)$. When input voltage is in low voltage range, the full bridge LLC resonant circuit $\left(\mathrm{S}_{1}-\mathrm{S}_{4}\right.$ are active,) is operated. On the other hand, the half bridge LLC resonant circuit $\left(\mathrm{S}_{1}\right.$ and $\mathrm{S}_{2}$ are active, $\mathrm{S}_{3} \mathrm{OFF}$ and $\mathrm{S}_{4} \mathrm{ON}$ ) is used under high voltage input case. Therefore, wide input voltage operation is achieved in this circuit topology. However, there is a dc voltage level on the resonant capacitor when LLC circuit is operated at half bridge circuit structure. A hybrid LLC converter [18] has been studied to achieve 8:1 wide output voltage operation $\left(\mathrm{V}_{\mathrm{o}, \max }=8 \mathrm{~V}_{\mathrm{o}, \min }\right)$. This circuit topology is based on a full bridge resonant circuit and an ac switch on the primary-side and a hybrid diode rectifier on the output-side. Compares to Reference [17], the half bridge LLC circuit with split input capacitors is used in Reference [18] to avoid a dc voltage level on the resonant capacitor under low voltage output operation. In order to extend output voltage range, a hybrid output rectifier with a full-wave rectification or a half-wave rectification structure is adopted on the secondary-side in Reference [18]. The main disadvantage of this circuit topology in Reference [18] is four diode conduction losses on the secondary-side when full-wave rectification structure is operated.

A new LLC converter is presented to realize wide range of input voltage operation. The LLC resonant circuit is used in the studied converter to achieve soft switching operation for all power devices due to inductive input impedance operation by pulse frequency modulation. To realize wide voltage input operation, the half bridge with split capacitors or full bridge equivalent LLC circuit can be operated on high-voltage side and the voltage doubler rectifier with different secondary turns is adopted on low-voltage side. Due to the different input voltage range, three circuit structures with different voltage gains are controlled to overcome wide range of input voltage variation. The input voltage range of the studied circuit topology is $50 \mathrm{~V}-400 \mathrm{~V}$. For high voltage input (200 V-400 V), half bridge LLC circuit with fewer winding turns is used to obtain the least voltage gain and regulate load voltage. For medium voltage input (100 V-200 V), full bridge LLC circuit with fewer secondary turns is controlled to attain high voltage gain. For low voltage input ( $50 \mathrm{~V}-100 \mathrm{~V})$, full bridge LLC circuit with more winding turns is adopted to obtain the largest voltage gain. Thus, the wide voltage operation $(50 \mathrm{~V}-400 \mathrm{~V})$ is realized in the studied LLC converter. Compared to the multistage converters or series/parallel converters, the proposed converter has simple circuit structure and control scheme by using the general analog integrated circuit. Compared to the $4: 1$ wide voltage LLC converter in 
Reference [17] with 4 switches (3 switches) conduction loss at low (high) voltage range, the proposed converter does not a dc voltage level on the resonant capacitor when half bridge LLC equivalent circuit structure with 4 switches conduction loss is operated and the proposed converter has 8:1 wide voltage operation capability. Compared to the 8:1 wide voltage LLC converter in Reference [18], the proposed converter has only two instead of four diode conduction losses on the secondary-side for high current output applications. The laboratory prototype has been developed and the experiments are given to investigate the presentation of the presented converter.

\section{Circuit Configuration}

The conventional LLC converters are provided in Figure 1. Figure 1a provides the converter schematic of the full bridge resonant circuit with center-tapped rectification and the voltage gain can be calculated as $V_{o} / V_{\text {in }}=G_{a c}\left(f_{s w}\right) n_{s} / n_{p}$, where $G_{a c}(f)$ is the transfer function of resonant tank by $L_{m}$, $L_{r}$ and $C_{r}$. The half bridge resonant circuit with center-tapped rectification is illustrated in Figure $1 b$. The voltage gain is calculated as $\mathrm{V}_{\mathrm{o}} / \mathrm{V}_{\mathrm{in}}=\mathrm{G}_{\mathrm{ac}}\left(\mathrm{f}_{\mathrm{sw}}\right) \mathrm{n}_{\mathrm{s}} /\left(2 \mathrm{n}_{\mathrm{p}}\right)$. Therefore, the full bridge LLC converter has two times of gain of the half bridge resonant circuit. However, the rectifier diodes $D_{1}$ and $D_{2}$ has at least $2 V_{o}$ voltage stress and more winding turns are needed on secondary-side. Figure $1 c, d$ are the other two circuit configurations with voltage doubler rectification. The voltage gains of Figure $1 \mathrm{c}, \mathrm{d}$ are obtained as $V_{\mathrm{o}} / \mathrm{V}_{\text {in }}=\mathrm{G}_{\mathrm{ac}}\left(\mathrm{f}_{\mathrm{sw}}\right)\left(2 \mathrm{n}_{\mathrm{s}}\right) / \mathrm{n}_{\mathrm{p}}$ and $\mathrm{V}_{\mathrm{o}} / \mathrm{V}_{\mathrm{in}}=\mathrm{G}_{\mathrm{ac}}\left(\mathrm{f}_{\mathrm{sw}}\right) \mathrm{n}_{\mathrm{s}} / \mathrm{n}_{\mathrm{p}}$, respectively. The voltage rating of $\mathrm{D}_{1}$ and $\mathrm{D}_{2}$ is $\mathrm{V}_{\mathrm{o}}$ and only one winding set of transformer is used on the output-side. Compared four circuit topologies in Figure 1, the full bridge LLC circuit with voltage double rectification has the largest voltage gain and the half bridge resonant circuit with center-tapped rectification has the least voltage gain.

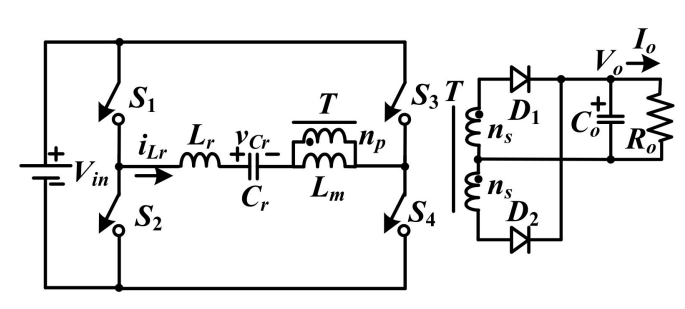

(a)

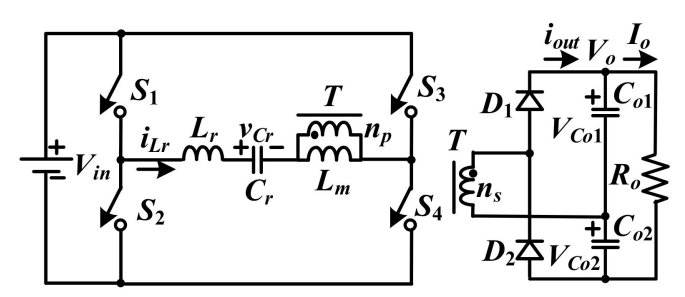

(c)

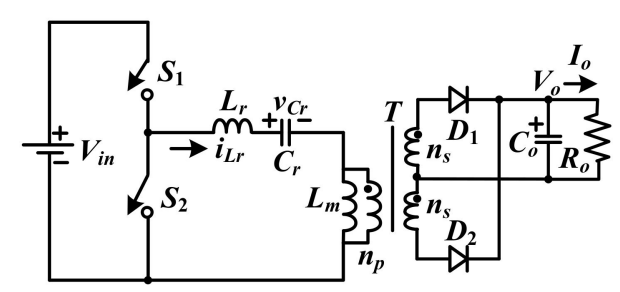

(b)

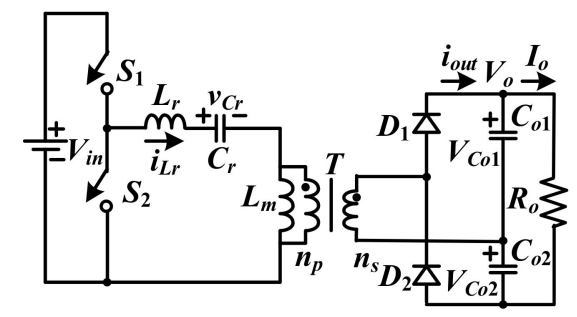

(d)

Figure 1. Diagram of the conventional inductor-inductor-capacitor (LLC) converters (a) full bridge resonant circuit with center-tapped rectification $(\mathbf{b})$ half bridge resonant circuit with center-tapped rectification (c) full bridge resonant circuit with voltage doubler rectification (d) half bridge resonant circuit with voltage doubler rectification.

The proposed converter diagram is shown in Figure 2a to have wide voltage input operation $(50 \mathrm{~V}-400 \mathrm{~V})$ such as solar power or renewable energy conversion. The proposed hybrid LLC converter includes a full bridge resonant circuit $\left(\mathrm{S}_{1}-\mathrm{S}_{4}, \mathrm{~L}_{\mathrm{r}}, \mathrm{C}_{\mathrm{r}}\right.$ and $\left.\mathrm{L}_{\mathrm{m}}\right)$ and a half bridge resonant circuit $\left(\mathrm{S}_{3}, \mathrm{~S}_{4}\right.$, $\mathrm{S}_{\mathrm{ac} 1}, \mathrm{~L}_{\mathrm{r}}, \mathrm{C}_{\mathrm{r}}$ and $\mathrm{L}_{\mathrm{m}}$ ) on the primary-side and the voltage doubler rectifier with $\mathrm{N}_{\mathrm{s}}$ and $2 \mathrm{~N}_{\mathrm{s}}$ winding turns on the secondary-side. The converter has three different operating sub-circuits for three voltage input regions (400 V-200 V, $200 \mathrm{~V}-100 \mathrm{~V}$ and $100 \mathrm{~V}-50 \mathrm{~V}$ ) as shown in Figure 2b-d. If each equivalent 
circuit in Figure $2 b-d$ is operated to have maximum voltage gain $G_{\max }=2$, then the proposed converter in Figure 2a can achieve wide voltage gain from $G_{\min }=1$ to $G_{\max }=8$. The passive elements $C_{r}, L_{r}$ and $\mathrm{L}_{\mathrm{m}}$ are the basic LLC resonant components. Due to frequency modulation, the LLC resonant tank is controlled to have an inductive input impedance characteristic and the fundamental input voltage of the resonant tank is leading to the fundamental input current. Power devices $S_{1}-S_{4}$ have soft switching turn-on characteristics. Power devices $\mathrm{S}_{\mathrm{ac} 1}$ and $\mathrm{S}_{\mathrm{ac} 2}$ are implemented by two back-to-back power MOSFETs. If $\mathrm{S}_{\mathrm{ac} 1}$ is $\mathrm{ON}(\mathrm{OFF})$, then half bridge (full bridge) resonant circuit is operated on primary-side. $\mathrm{S}_{\mathrm{ac} 2}$ is used to determine $2 \mathrm{~N}_{\mathrm{S}}$ or $\mathrm{N}_{\mathrm{s}}$ secondary turns connecting to output-side. In the proposed converter, the circuit needs low (or high) voltage gain under high (or low) voltage input case to control load voltage. If $400 \mathrm{~V}>\mathrm{V}_{\text {in }}>200 \mathrm{~V}$ (high voltage region $\mathrm{V}_{\mathrm{in}-\mathrm{H}}$, Figure $2 \mathrm{~b}, \mathrm{~S}_{1}, \mathrm{~S}_{2}$ and $\mathrm{S}_{\mathrm{ac} 2}$ turn off, $S_{\text {ac1 }}$ turns on and $S_{3}$ and $S_{4}$ are controlled by pulse frequency modulation. The square wave voltage $\mathrm{v}_{\mathrm{ab}}$ has voltage amplitudes of $\pm \mathrm{V}_{\mathrm{in}} / 2$ and the magnetizing inductor voltage $\mathrm{v}_{\mathrm{Lm}}$ has voltage amplitudes of $\pm n_{p} V_{o} /\left(2 n_{s}\right)$. The voltage gain in Figure $2 b$ is expressed as $V_{o} / V_{i n-H}=G_{a c}\left(f_{s w}\right) n_{s} / n_{p}$, where $G_{a c}(f)$ is the transfer function of the resonant tank by $\mathrm{L}_{\mathrm{m}}, \mathrm{C}_{\mathrm{r}}$ and $\mathrm{L}_{\mathrm{r}}$. If $200 \mathrm{~V}>\mathrm{V}_{\text {in }}>100 \mathrm{~V}$ (medium voltage region $\mathrm{V}_{\mathrm{in}-\mathrm{M}}$, Figure $2 \mathrm{c}, \mathrm{S}_{\mathrm{ac} 1}$ and $\mathrm{S}_{\mathrm{ac} 2}$ turn off and $\mathrm{S}_{1}-\mathrm{S}_{4}$ are controlled by pulse frequency modulation. The square wave voltage $v_{a b}$ has voltage amplitudes of $\pm V_{\text {in }}$ and the magnetizing inductor voltage $v_{L m}$ has voltage amplitudes of $\pm n_{p} V_{o} /\left(2 n_{s}\right)$. The voltage gain in Figure $2 c$ is $V_{o} / V_{i n-M}=G_{a c}\left(f_{s w}\right)\left(2 n_{s}\right) / n_{p}$. If $100 \mathrm{~V}>\mathrm{V}_{\text {in }}>50 \mathrm{~V}$ (low voltage region $\mathrm{V}_{\text {in-L }}$, Figure $2 \mathrm{~d}, \mathrm{~S}_{\text {ac1 }}$ turns off, $\mathrm{S}_{\mathrm{ac} 2}$ turns on and $\mathrm{S}_{1}-\mathrm{S}_{4}$ are controlled by pulse frequency modulation. The square wave voltage $v_{a b}$ has voltage amplitudes of $\pm V_{\text {in }}$ and the magnetizing inductor voltage $v_{L m}$ has voltage amplitudes of $\pm n_{p} V_{o} /\left(4 n_{s}\right)$. The voltage gain is $\mathrm{V}_{\mathrm{o}} / \mathrm{V}_{\mathrm{in}-\mathrm{L}}=\mathrm{G}_{\mathrm{ac}}\left(\mathrm{f}_{\mathrm{sw}}\right)\left(4 \mathrm{n}_{\mathrm{s}}\right) / \mathrm{n}_{\mathrm{p}}$. From the obtained voltage gains in high, medium and low voltage input regions, it is observed that the circuit has the largest gain $\mathrm{G}_{\mathrm{ac}}\left(\mathrm{f}_{\mathrm{sw}}\right)\left(4 \mathrm{n}_{\mathrm{s}}\right) / \mathrm{n}_{\mathrm{p}}$ under low voltage input region $(50 \mathrm{~V}-100 \mathrm{~V})$ and least voltage gain $\mathrm{G}_{\mathrm{ac}}\left(\mathrm{f}_{\mathrm{sw}}\right) \mathrm{n}_{\mathrm{s}} / \mathrm{n}_{\mathrm{p}}$ at high voltage input region $(200 \mathrm{~V}-400 \mathrm{~V})$.

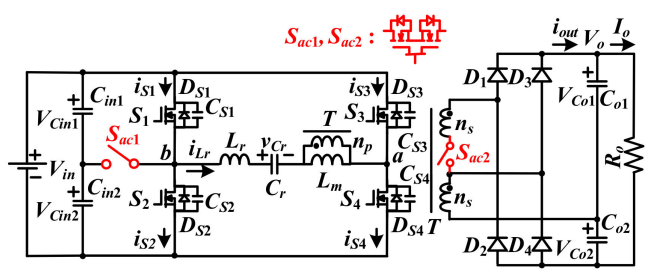

(a)

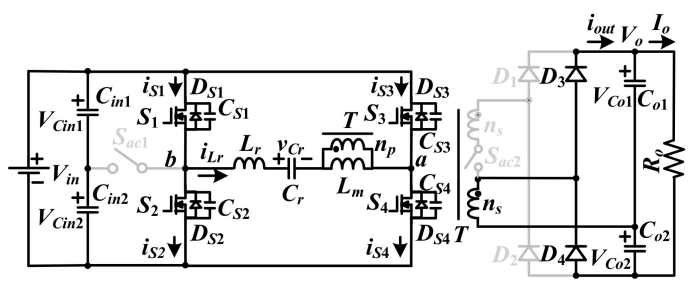

(c)

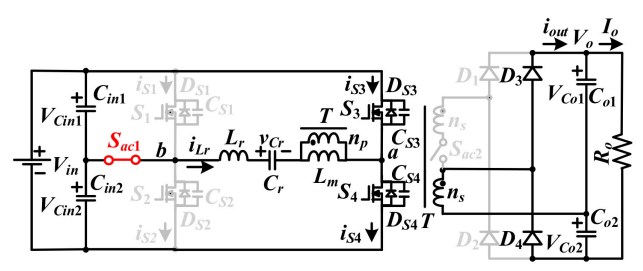

(b)

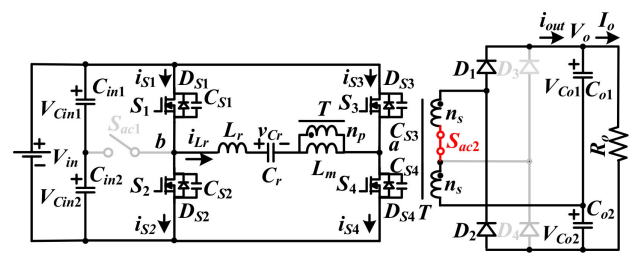

(d)

Figure 2. Circuit schematics (a) the proposed converter (b) high voltage input region (200 V-400 V) (c) medium voltage input region $(100 \mathrm{~V}-200 \mathrm{~V})$ (d) low voltage input region (50 V-100 V).

\section{Circuit Analysis and Principle of Operation}

From the ON-OFF states of $\mathrm{S}_{\mathrm{ac} 1}$ and $\mathrm{S}_{\mathrm{ac} 2}$ in Figure $2 \mathrm{~b}-\mathrm{d}$, the proposed LLC converter can be controlled under three voltage input regions: $\mathrm{V}_{\text {in- } \mathrm{H}}: 400 \mathrm{~V}-200 \mathrm{~V}$ (high voltage region), $\mathrm{V}_{\text {in-M }}$ : $200 \mathrm{~V}-100 \mathrm{~V}$ (medium voltage region) and $\mathrm{V}_{\text {in-L }}: 100 \mathrm{~V}-50 \mathrm{~V}$ (low voltage region). When $\mathrm{V}_{\text {in }}$ is in the high voltage, the converter only needs low voltage gain to control load voltage. Therefore, $S_{a c 1}$ turns on and $S_{a c 2}, S_{1}$ and $S_{2}$ turn off. The half bridge LLC resonant circuit and low secondary turns are used in Figure $2 b . S_{3}$ and $S_{4}$ are operated with frequency control. According to the resonant circuit by $L_{r}, C_{r}$, 
$L_{m}$ and $R_{o}$, the voltage gain under high voltage input region is $V_{o} / V_{i n-H}=n_{s} G_{a c}\left(f_{s w}\right) / n_{p}$, where $G_{a c}(f)$ is the transfer function by $L_{r}, C_{r}, L_{m}$ and $R_{o}$. The LLC converter has four or six operating modes under $\mathrm{f}_{\mathrm{sW}}$ (switching frequency) $>$ or $<\mathrm{f}_{\mathrm{r}}$ (resonant frequency). Since the converter is designed to have wide voltage gain, $\mathrm{f}_{\mathrm{sw}}$ is always less than or close to $\mathrm{f}_{\mathrm{r}}$. Therefore, the zero-voltage switching (ZVS) of $\mathrm{S}_{3}$ and $\mathrm{S}_{4}$ and zero-current switching (ZCS) of $\mathrm{D}_{3}$ and $\mathrm{D}_{4}$ are accomplished. The PWM waveforms of LLC converter operated for high voltage region are illustrated in Figure $3 \mathrm{a}$ and the Figure $3 \mathrm{~b}-\mathrm{g}$ provide the equivalent circuits for modes 1-6 for one switching cycle.

a. Mode $1\left[t_{0}, t_{1}\right]$ : At $t_{0}, v_{C S 4}=0$. The current $i_{L r}$ flows through $D_{S 4}$ and $S_{4}$ turns on at this instant to have ZCS operation. The secondary current is positive so that $\mathrm{D}_{3}$ is conducting and capacitor $\mathrm{C}_{\mathrm{o} 1}$ is charged. The components $\mathrm{C}_{\mathrm{r}}$ and $\mathrm{L}_{\mathrm{r}}$ are naturally resonant and the resonant frequency $\mathrm{f}_{\mathrm{r}} \approx 1 / 2 \pi \sqrt{\mathrm{L}_{\mathrm{r}} \mathrm{C}_{\mathrm{r}}}$.

b. Mode $2\left[t_{1}, t_{2}\right]$ : Since $f_{r}>f_{S w}, i_{D 3}$ is decreased to zero at $t_{1}$ with ZCS operation and $\mathrm{i}_{\mathrm{Lr}}\left(\mathrm{t}_{1}\right)=\mathrm{i}_{\mathrm{Lm}}\left(\mathrm{t}_{1}\right)$. Thus, the load current $\mathrm{I}_{\mathrm{o}}$ will discharge $\mathrm{C}_{\mathrm{o} 1}$ and $\mathrm{C}_{\mathrm{o} 2}$. The current $\mathrm{i}_{\mathrm{Lm}}\left(\mathrm{t}_{2}\right)$ is obtained $\mathrm{i}_{\mathrm{Lm}}\left(\mathrm{t}_{2}\right) \approx\left(\mathrm{n}_{\mathrm{p}} \mathrm{V}_{\mathrm{o}}\right) /\left(8 \mathrm{n}_{\mathrm{s}} \mathrm{L}_{\mathrm{m}} \mathrm{f}_{\mathrm{sw}}\right)$.

c. Mode $3\left[t_{2}, t_{3}\right]$ : Power device $S_{4}$ turns off at $t_{2}$. $i_{L r}\left(t_{2}\right)$ will discharge (charge) $C_{S 3}\left(C_{S 4}\right)$. Due to $\mathrm{i}_{\mathrm{Lr}}\left(\mathrm{t}_{2}\right)<\mathrm{i}_{\mathrm{Lm}}\left(\mathrm{t}_{2}\right), \mathrm{D}_{4}$ will naturally conduct and capacitor voltage $\mathrm{v}_{\mathrm{Co} 2}$ is increased.

d. Mode $4\left[t_{3}, t_{4}\right]$ : At the start of this mode, the capacitor voltage $v_{C S 3}=0$. $i_{L r}\left(t_{3}\right)$ is positive and $D_{S 3}$ is conducting so that $S_{3}$ can turn on at this instant to accomplish ZVS. In mode 4 , the resonant tank transfers power from input terminal $V_{\text {in }}$ to output terminal $V_{0}$.

e. Mode $5\left[t_{4}, t_{5}\right]$ : The diode current $i_{D 4}$ will naturally turn off at $t_{4}$ due to $f_{r}>f_{S W}$. In this mode, the load current $I_{0}$ discharges $C_{01}$ and $C_{o 2}$. The current $i_{L m}\left(t_{5}\right)$ is obtained $\mathrm{i}_{\mathrm{Lm}}\left(\mathrm{t}_{5}\right) \approx-\left(\mathrm{n}_{\mathrm{p}} \mathrm{V}_{\mathrm{o}}\right) /\left(8 \mathrm{n}_{\mathrm{s}} \mathrm{L}_{\mathrm{m}} \mathrm{f}_{\mathrm{Sw}}\right)$

f. Mode $6\left[t_{5}, T_{s w}+t_{0}\right]: S_{3}$ turns off at the start of this mode. $i_{L r}\left(t_{5}\right)$ discharge (charge) $C_{S 4}\left(C_{S 3}\right)$ and $\mathrm{D}_{3}$ start conducting. To achieve zero-voltage switching of $\mathrm{S}_{4},\left|\mathrm{i}_{\mathrm{Lm}}\left(\mathrm{t}_{5}\right)\right|$ must be greater than $\mathrm{V}_{\mathrm{in}-\mathrm{H}} \sqrt{2 \mathrm{C}_{\mathrm{oss}} /\left(\mathrm{L}_{\mathrm{m}}+\mathrm{L}_{\mathrm{r}}\right)}$. At the end of this mode, $\mathrm{v}_{\mathrm{CS} 4}=0$.

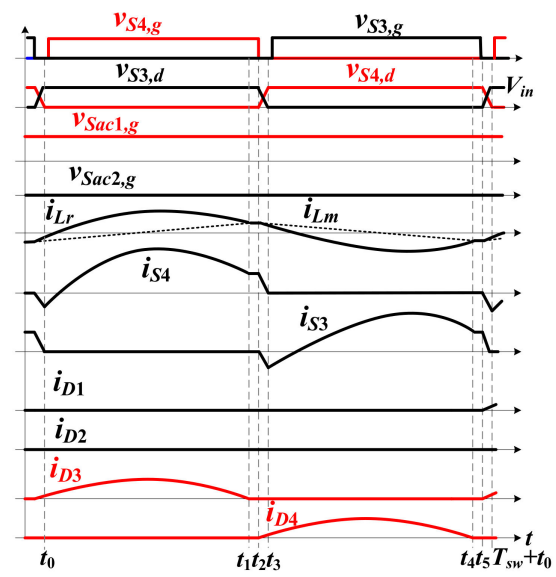

(a)

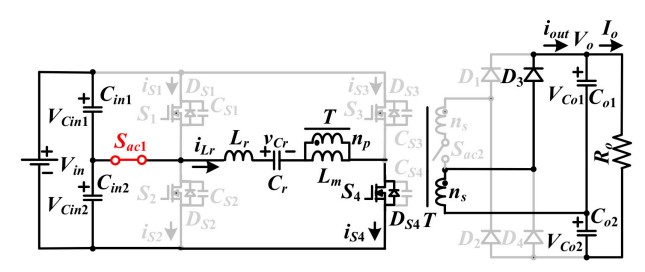

(b)

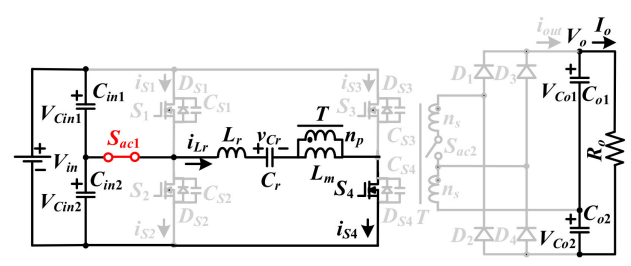

(c)

Figure 3. Cont. 


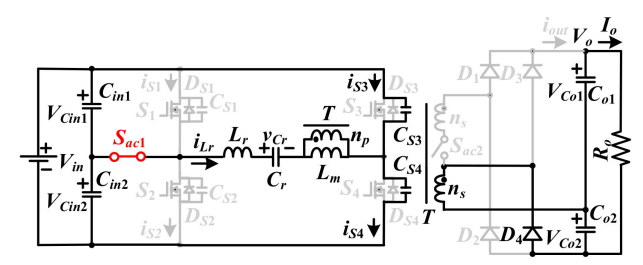

(d)

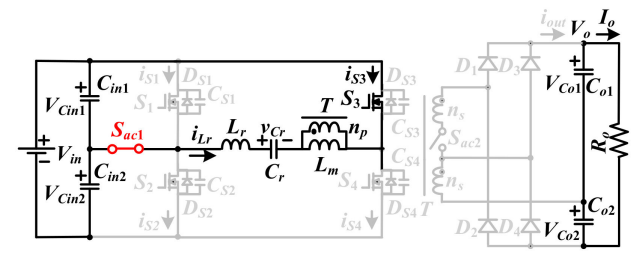

(f)

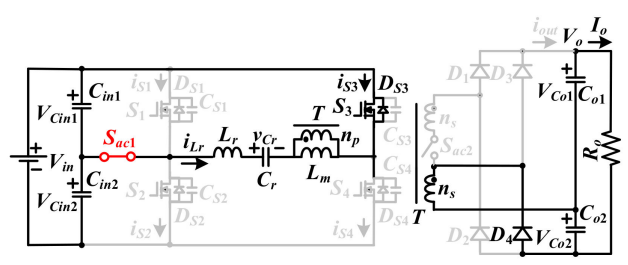

(e)

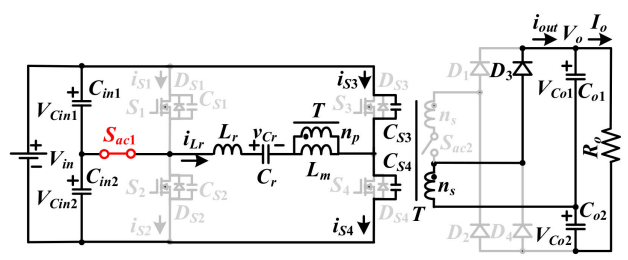

(g)

Figure 3. Presented converter under high voltage input region (a) pulse-width modulation (PWM) signals (b) mode 1 equivalent circuit (c) mode 2 equivalent circuit (d) mode 3 equivalent circuit (e) mode 4 equivalent circuit (f) mode 5 equivalent circuit (g) mode 6 equivalent circuit.

When $\mathrm{V}_{\text {in }}$ is in medium voltage region $\left(\mathrm{V}_{\mathrm{in}-\mathrm{M}}: 100 \mathrm{~V}-200 \mathrm{~V}\right), \mathrm{S}_{\mathrm{ac} 1}$ and $\mathrm{S}_{\mathrm{ac} 2}$ turn off. The full bridge LLC circuit and low secondary turns are used in Figure 2c. The FM scheme is used to control $\mathrm{S}_{1}-\mathrm{S}_{4}$. The converter has gain $\mathrm{V}_{\mathrm{o}} / \mathrm{V}_{\mathrm{in}-\mathrm{M}}=2 \mathrm{G}_{\mathrm{ac}}\left(\mathrm{f}_{\mathrm{sW}}\right) \mathrm{n}_{\mathrm{s}} / \mathrm{n}_{\mathrm{p}}$. The PWM signals and the corresponding circuits are illustrated in Figure 4 for medium voltage input condition.

a. $\quad$ Mode $1\left[t_{0}, t_{1}\right]$ : This mode starts at $t_{0}$ if the drain voltages $v_{S 4, d}=v_{S 1, d}=0 . i_{L r}$ flows through $D_{S 4}$ and $D_{S 1}$ so that $S_{4}$ and $S_{1}$ can turn on with ZVS operation. Since $i_{L r}\left(t_{0}\right)>i_{L m}\left(t_{0}\right)$, it can observe that $\mathrm{D}_{3}$ conducts, $\mathrm{v}_{\mathrm{Lm}} \approx\left(\mathrm{n}_{\mathrm{p}} \mathrm{V}_{\mathrm{o}}\right) /\left(2 \mathrm{n}_{\mathrm{s}}\right)$. The resonant frequency by passive elements $\mathrm{L}_{\mathrm{r}}$ and $\mathrm{C}_{\mathrm{r}}$ in mode 1 is $f_{r}=1 /\left[2 \pi \sqrt{L_{r} C_{r}}\right]$. The load current $I_{o}$ discharges $C_{o 2}$ and $i_{D 3}$ charges $C_{o 1}$.

b. Mode $2\left[t_{1}, t_{2}\right]$ : If $f_{S W}>f_{r}, D_{3}$ will naturally turn off at $t_{1}$. This mode ends at $t_{2}$ and $\mathrm{i}_{\mathrm{Lm}}\left(\mathrm{t}_{2}\right) \approx\left(\mathrm{n}_{\mathrm{p}} \mathrm{V}_{\mathrm{o}}\right) /\left(8 \mathrm{n}_{\mathrm{s}} \mathrm{L}_{\mathrm{m}} \mathrm{f}_{\mathrm{sw}}\right)$.

c. Mode $3\left[t_{2}, t_{3}\right]$ : At $t_{2}, S_{4}$ and $S_{1}$ turn off. $i_{L r}\left(t_{2}\right)$ discharges $C_{S 3}$ and $C_{S 2}$. Since $i_{L m}\left(t_{2}\right)>i_{L r}\left(t_{2}\right)$, the diode $\mathrm{D}_{4}$ is forward biased. To realize ZVS turn-on of $S_{3}$ and $S_{2}$, the current $i_{L m}\left(t_{2}\right)$ must be greater than $\mathrm{V}_{\mathrm{in}, \mathrm{M}} \sqrt{\mathrm{C}_{\mathrm{oss}} /\left(\mathrm{L}_{\mathrm{m}}+\mathrm{L}_{\mathrm{r}}\right)}$.

d. Mode $4\left[t_{3}, t_{4}\right]$ : At $t_{3}, C_{S 3}$ and $C_{S 2}$ are discharged to zero. $i_{L r}\left(t_{3}\right)$ is positive so that $D_{S 2}$ and $D_{s 3}$ are conducting. Thus, the zero-voltage switching of $S_{3}$ and $S_{2}$ can be achieved after time $t_{3}$. Owing to $\mathrm{i}_{\mathrm{Lm}}\left(\mathrm{t}_{3}\right)>\mathrm{i}_{\mathrm{Lr}}\left(\mathrm{t}_{3}\right), \mathrm{D}_{4}$ conducts, $\mathrm{v}_{\mathrm{Lm}} \approx-\left(\mathrm{V}_{\mathrm{o}} \mathrm{n}_{\mathrm{p}}\right) /\left(2 \mathrm{n}_{\mathrm{s}}\right)$ and $\mathrm{i}_{\mathrm{Lm}}$ decreases. $\mathrm{C}_{\mathrm{o} 2}$ is charged.

e. Mode $5\left[t_{4}, t_{5}\right]$ : Since $f_{r}>f_{s w}, D_{4}$ will naturally turn off at $t_{4}$. The current $i_{L m}\left(t_{5}\right)$ is equal to $-\left(\mathrm{n}_{\mathrm{p}} \mathrm{V}_{\mathrm{o}}\right) /\left(8 \mathrm{n}_{\mathrm{s}} \mathrm{L}_{\mathrm{m}} \mathrm{f}_{\mathrm{sw}}\right)$.

f. $\quad$ Mode $6\left[t_{5}, T_{s w}+t_{0}\right]$ : At $t_{5}$, power devices $S_{3}$ and $S_{2}$ are turned off. Since $i_{L r}\left(t_{5}\right)<0, C_{S 4}$ and $\mathrm{C}_{\mathrm{S} 1}$ discharge in this mode. To realize ZVS turn-on of $\mathrm{S}_{4}$ and $\mathrm{S}_{1}$, the current $\left|\mathrm{i}_{\mathrm{Lm}}\left(\mathrm{t}_{5}\right)\right|$ must be greater than $\mathrm{V}_{\mathrm{in}, \mathrm{M}} \sqrt{\mathrm{C}_{\mathrm{oss}} /\left(\mathrm{L}_{\mathrm{m}}+\mathrm{L}_{\mathrm{r}}\right)}$. The mode 6 ends at time $\mathrm{T}_{\mathrm{sw}}+\mathrm{t}_{0}$ when $\mathrm{v}_{\mathrm{CS} 1}=\mathrm{v}_{\mathrm{CS} 4}=0$. 


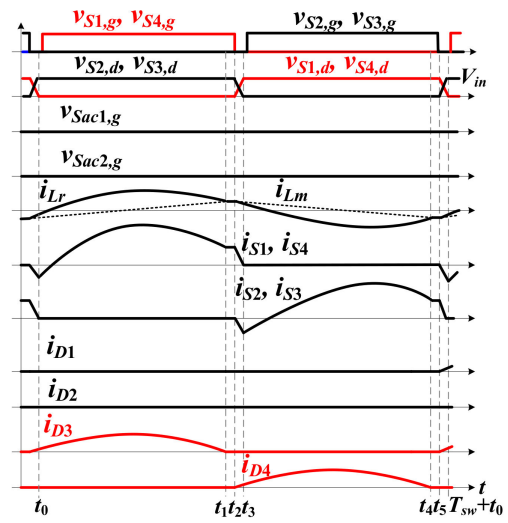

(a)

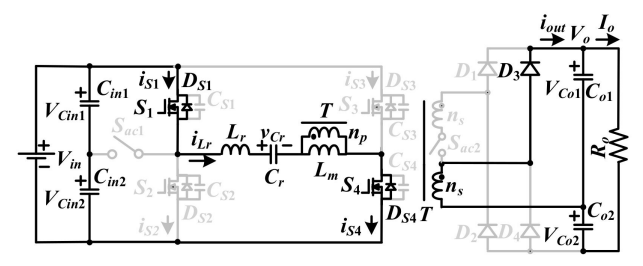

(b)

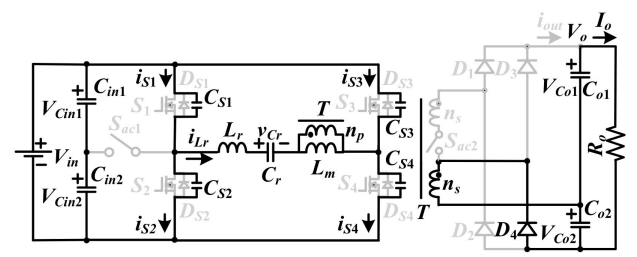

(d)

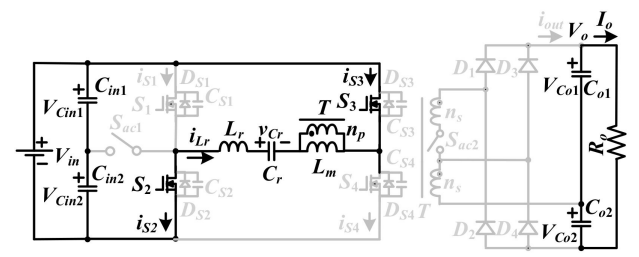

(f)

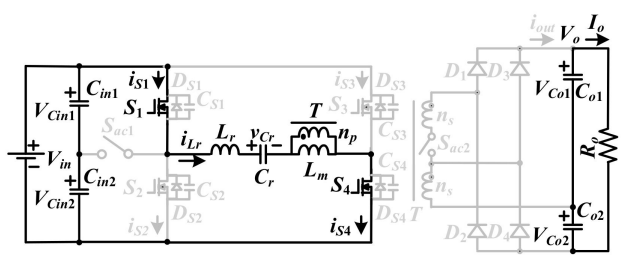

(c)

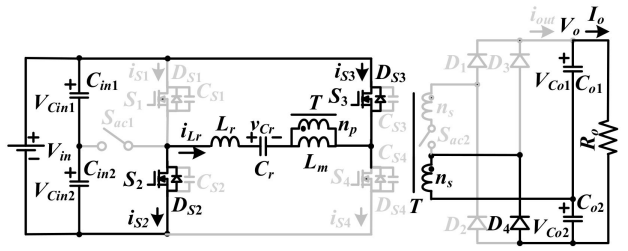

(e)

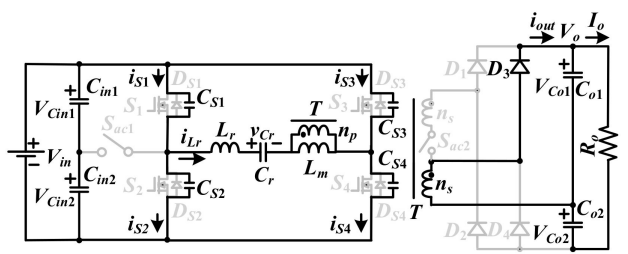

(g)

Figure 4. Presented converter under medium voltage input region (a) PWM signals (b) mode 1 equivalent circuit (c) mode 2 equivalent circuit (d) mode 3 equivalent circuit (e) mode 4 equivalent circuit (f) mode 5 equivalent circuit (g) mode 6 equivalent circuit.

If $50 \mathrm{~V}<\mathrm{V}_{\text {in }}<100 \mathrm{~V}$ (low voltage region, $\mathrm{V}_{\text {in-L }}$ ), $\mathrm{S}_{\text {ac1 }}$ turns off and $\mathrm{S}_{\text {ac2 } 2}$ turns on. The LLC circuit and $2 \mathrm{~N}_{\mathrm{S}}$ secondary turns are used in Figure $2 \mathrm{~d}$. For low voltage input region, the converter has gain $\mathrm{V}_{\mathrm{o}} / \mathrm{V}_{\mathrm{in}-\mathrm{L}}=4 \mathrm{G}_{\mathrm{ac}}\left(\mathrm{f}_{\mathrm{sw}}\right) \mathrm{n}_{\mathrm{s}} / \mathrm{n}_{\mathrm{p}}$. It can observe the proposed converter under low voltage input region has the largest voltage gain compared to the high and medium voltage regions. Figure 5 illustrates the PWM signals and the corresponding mode circuits.

a. Mode $1\left[\mathbf{t}_{\mathbf{0}}, \mathbf{t}_{\mathbf{1}}\right]$ : At time $\mathrm{t}_{0}, \mathrm{v}_{\mathrm{CS} 4}=\mathrm{v}_{\mathrm{CS} 1}=0 . \mathrm{D}_{\mathrm{S} 4}$ and $\mathrm{D}_{\mathrm{S} 1}$ turn on due to $\mathrm{i}_{\mathrm{Lr}}\left(\mathrm{t}_{0}\right)<0$. The zero-voltage switching of $S_{4}$ and $S_{1}$ are achieved after time $t_{0}$. $i_{L r}\left(t_{0}\right)>i_{L m}\left(t_{0}\right)$ and $D_{1}$ is conducting.

b. Mode $2\left[t_{1}, t_{2}\right]$ : Since $f_{r}>f_{s w}, D_{1}$ will naturally turn off at $t_{1}$ and $i_{L r}\left(t_{1}\right)=i_{L m}\left(t_{1}\right)$. The load current $\mathrm{I}_{\mathrm{o}}$ discharges $\mathrm{C}_{\mathrm{o} 1}$ and $\mathrm{C}_{\mathrm{o} 2} . \mathrm{C}_{\mathrm{r}}, \mathrm{L}_{\mathrm{m}}$ and $\mathrm{L}_{\mathrm{r}}$ are naturally resonant with frequency $\mathrm{f}_{\mathrm{p}}$.

c. Mode 3 [ $t_{2}-t_{3}$ ]: At $t_{2}, S_{4}$ and $S_{1}$ turn off. $i_{L r}\left(t_{2}\right)$ discharges $C_{S 3}$ and $C_{S 2}$. Since $i_{L r}\left(t_{2}\right)<i_{L m}\left(t_{2}\right)$, $\mathrm{D}_{2}$ is forward biased and $\mathrm{v}_{\mathrm{Co} 2}$ is increased. 
d. Mode $4\left[t_{3}, t_{4}\right]$ : Mode 4 starts at $t_{3}$ when $C_{S 3}$ and $C_{S 2}$ are discharged to zero voltage. $i_{L r}\left(t_{3}\right)$ is positive so that $D_{S 3}$ and $D_{S 2}$ are conducting. $S_{3}$ and $S_{2}$ turn on at this moment to have ZVS operation.

e. Mode $5\left[t_{4}, t_{5}\right]$ : If $f_{r}>f_{s w}, D_{2}$ will turn off with zero-current switching at $t_{4}$. The load current $I_{o}$ discharges $\mathrm{C}_{\mathrm{o} 1}$ and $\mathrm{C}_{\mathrm{o} 2}$.

f. Mode $6\left[t_{5}, T_{s w}+t_{0}\right]$ : This mode starts at $t_{5}$, when $S_{3}$ and $S_{2}$ turn off. $i_{\text {Lr }}\left(t_{5}\right)$ will discharge (charge) $C_{S 4}$ and $C_{S 1}$ and $D_{1}$ is forward biased. This mode ends at $T_{s w}+t_{0}$ when $v_{C S 4}=v_{C S 1}=0$.

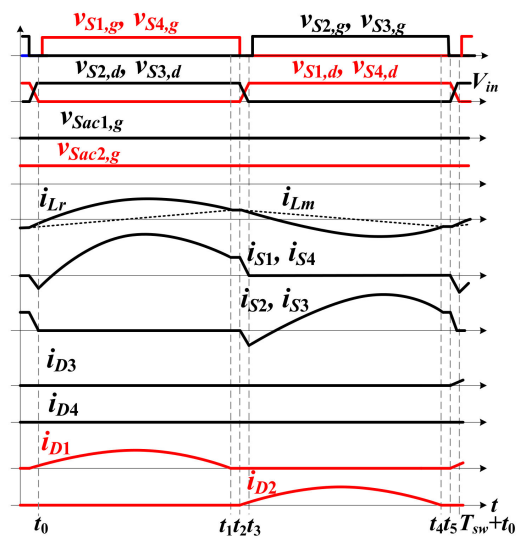

(a)

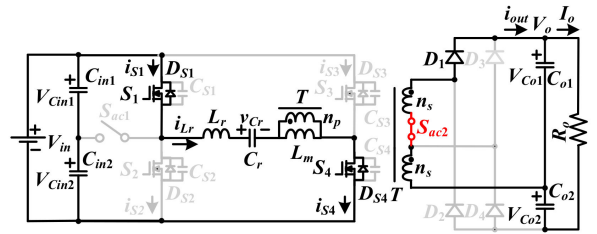

(b)

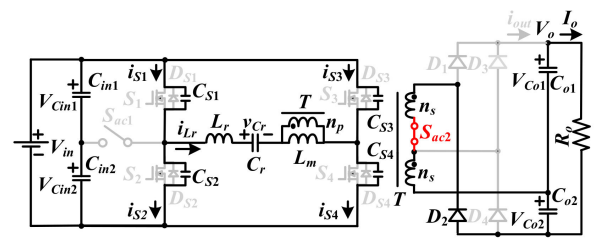

(d)

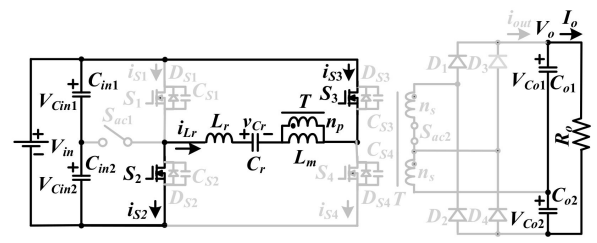

(f)

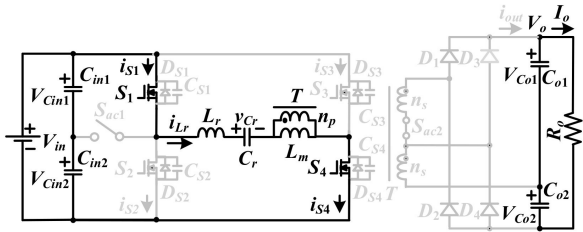

(c)

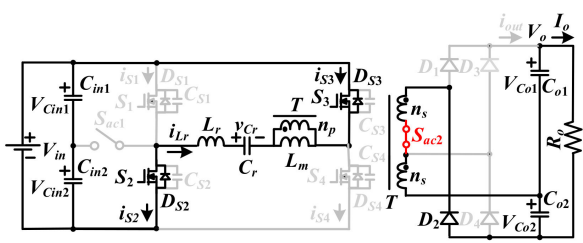

(e)

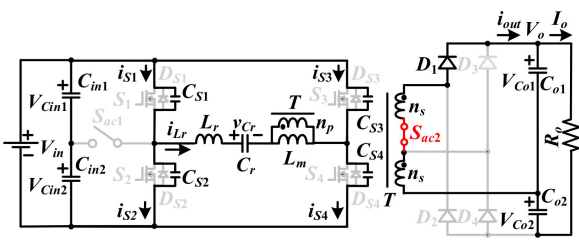

(g)

Figure 5. Presented converter under low voltage input region (a) PWM signals (b) mode 1 equivalent circuit (c) mode 2 equivalent circuit (d) mode 3 equivalent circuit (e) mode 4 equivalent circuit (f) mode 5 equivalent circuit $(\mathrm{g})$ mode 6 equivalent circuit.

\section{Circuit Characteristics and Design Example}

Based on the input voltage regions, $S_{a c 1}$ and $S_{a c 2}$ are controlled at on or off state. Therefore, the converter can be operated at three input voltage regions. Full bridge (half bridge) LLC converter is operated to have low (high) voltage gain for low (high) voltage input region. The equivalent resonant 
circuit is derived in Figure 6a. According to the PWM signals of $S_{1}-S_{4}$, the square wave voltage $V_{a c}$ is generated. If full bridge LLC converter with $S_{1}-S_{4}$ is operated, the voltage $V_{a c}$ has voltage values $\pm V_{\text {in }}$ in Figure 2c, d. If the half bridge LLC converter with $S_{3}$ and $S_{4}$ shown in Figure $2 b$ is operated, the voltage $V_{a c}$ has voltage values $\pm V_{i n} / 2$. For medium and high voltage input regions shown in Figure $2 b, c, S_{a c 2}$ is off. It can obtain the inductor voltage $V_{L m}=n V_{o} / 2$ or $-n V_{o} / 2$, where $n=n_{p} / n_{s}$, if $D_{3}$ or $\mathrm{D}_{4}$ is conducting. For low voltage input region (Figure $2 d$ ), The inductor voltage $V_{\mathrm{Lm}}=n V_{\mathrm{o}} / 4$ or $-n V_{\mathrm{o}} / 4$ if $\mathrm{D}_{1}$ or $\mathrm{D}_{2}$ is conducting. In Figure $6 \mathrm{a}$, the input-side and output-side of the resonant tank are all square voltage waveforms. Based on the Fourier Series Analysis (FSA), the square voltage waveform is expressed as the summation of the fundamental frequency component and the higher order harmonic frequency components. Thus, the circuit analysis of the resonant circuit in Figure 6a is related to the nonlinear and nonsinusoidal circuit analysis. If the output voltage at higher order harmonic frequencies are less than the fundamental harmonic voltage, then only the fundamental harmonic of square voltage wave is considered in Figure $6 \mathrm{~b}$ to simply the circuit analysis and design the resonant converter. The fundamental harmonic approximation (FHA) approach has acceptable design results if the LLC converter is operated at or close to the resonant frequency $f_{r}$. In Figure $6 b$, the rms values of fundamental harmonic voltage at input and output side are given as.

$$
\begin{aligned}
& \mathrm{V}_{\mathrm{ac}, \mathrm{f}}=\left\{\begin{array}{c}
\frac{2 \sqrt{2} \mathrm{~V}_{\mathrm{in}}}{\pi}, \mathrm{S}_{\mathrm{ac}, 1} \text { off } \\
\frac{\sqrt{2} \mathrm{~V}_{\mathrm{in}}}{\pi}, \mathrm{S}_{\mathrm{ac}, 1} \text { on }
\end{array}\right. \\
& \mathrm{V}_{\mathrm{Lm}, \mathrm{f}}=\left\{\begin{array}{c}
\sqrt{2} \mathrm{nV}_{\mathrm{o}} / \pi, \mathrm{S}_{\mathrm{ac} 2} \text { off } \\
\mathrm{nV}_{\mathrm{o}} /(\sqrt{2} \pi), \mathrm{S}_{\mathrm{ac} 2} \text { on }
\end{array}\right.
\end{aligned}
$$

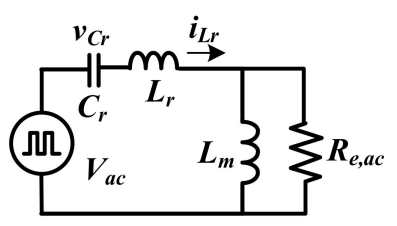

(a)

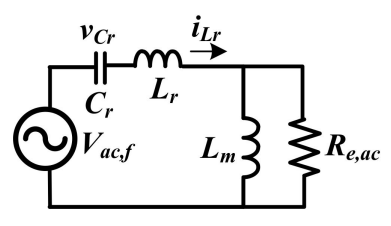

(b)

Figure 6. The equivalent resonant circuit of the proposed LLC converter with (a) nonlinear nonsinusoidal circuit (b) linear sinusoidal circuit.

The ac equivalent load resistance $R_{e, a c}$ can be obtained according to power balance between praimary and secondary sides of trnasformer.

$$
\mathrm{P}_{\mathrm{ac}}=\left(\mathrm{V}_{\mathrm{Lm}, \mathrm{f}}\right)^{2} / \mathrm{R}_{\mathrm{e}, \mathrm{ac}}=\mathrm{P}_{\mathrm{o}}=\left(\mathrm{V}_{\mathrm{o}}\right)^{2} / \mathrm{R}_{\mathrm{o}}
$$

From Equations (2) and (3), the ac equivalent load resistance is calculated as.

$$
R_{e, a c}=\left\{\begin{array}{c}
2 n^{2} R_{o} / \pi^{2}, S_{a c 2} \text { off } \\
n^{2} R_{o} /\left(2 \pi^{2}\right), S_{a c 2} \text { on }
\end{array} .\right.
$$

From the linear circuit in Figure 6b, the voltage transfer function can be approximated by using the fundamental input and output voltages.

$$
\mathrm{G}_{\mathrm{ac}}\left(\mathrm{f}_{\mathrm{sw}}\right)=\left|\left(\mathrm{j} \mathrm{X}_{\mathrm{LM}} / / \mathrm{R}_{\mathrm{e}, \mathrm{ac}}\right) /\left[\left(\mathrm{j} \mathrm{X}_{\mathrm{LM}} / / \mathrm{R}_{\mathrm{e}, \mathrm{ac}}\right)+\mathrm{j} \mathrm{X}_{\mathrm{Lr}}-\mathrm{jX} \mathrm{Cr}\right]\right|=\left(\mathrm{V}_{\mathrm{Lm}, \mathrm{f}}\right)^{2} /\left(\mathrm{V}_{\mathrm{ac}, \mathrm{f}}\right)^{2},
$$

where $X_{L m}=2 \pi f_{S w} L_{m}, X_{L r}=2 \pi f_{s w} L_{r}$ and $X_{C r}=1 /\left(2 \pi f_{s w} C_{r}\right)$. From Equations (1), (2) and (5), the voltage transfer function $G_{a c}\left(f_{S W}\right)$ is obtained in Equations (6)-(8) for high, medium and low voltage input regions. 


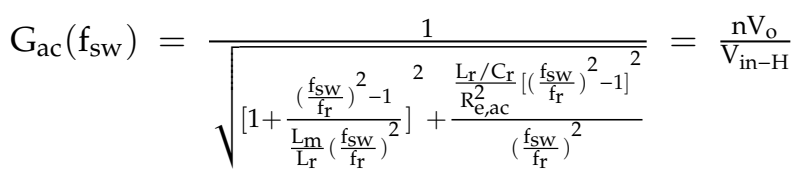

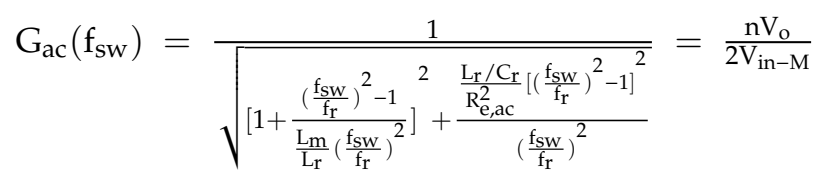

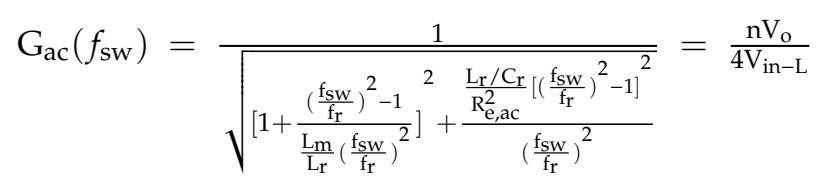

Therefore, the load voltage $\mathrm{V}_{\mathrm{o}}$ can be obtained under different input voltage conditions and expressed in Equations (9)-(11) for high, medium and low voltage input regions, respectively.

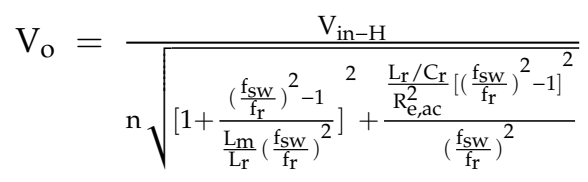

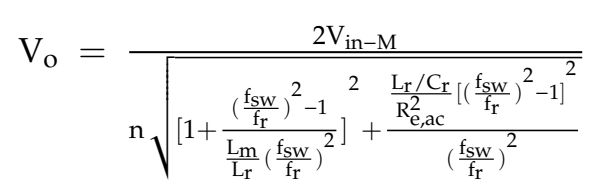

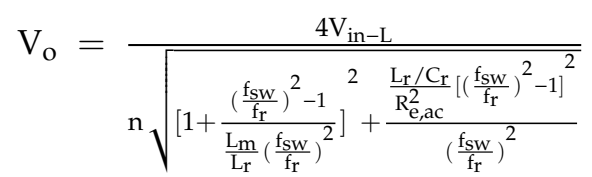

The studied LLC converter is operated under wide voltage input (50-400 V), the load voltage $\mathrm{V}_{\mathrm{o}}$ is $48 \mathrm{~V}$ and load power is $500 \mathrm{~W}$. The resonant frequency $\mathrm{f}_{\mathrm{r}}$ is designed at $100 \mathrm{kHz}$. The selected magnetizing and resonant inductances are $\mathrm{L}_{\mathrm{m}}=6 \mathrm{~L}_{\mathrm{r}}$. For high $\left(\mathrm{V}_{\mathrm{in}-\mathrm{H}}, 200 \mathrm{~V}-400 \mathrm{~V}\right)$, medium $\left(\mathrm{V}_{\text {in- } \mathrm{M}}\right.$, $100 \mathrm{~V}-200 \mathrm{~V})$ and low $\left(\mathrm{V}_{\text {in- } \mathrm{L}}, 50 \mathrm{~V}-100 \mathrm{~V}\right)$ voltage input ranges, the equivalent resonant circuit models in Figure $6 \mathrm{~b}$ are identical. Thus, the converter operated at high voltage input region is designed in the following discussion. According to Equation (6), it is clear that the proposed converter has the minimum voltage gain at $\mathrm{V}_{\text {in }}=400 \mathrm{~V}$ and has the maximum voltage gain at $\mathrm{V}_{\text {in }}=200 \mathrm{~V}$. It is assumed that the dc gain at $V_{\text {in }}=400 \mathrm{~V}$ input is designed as 0.95 . From Equation (6), the primary-secondary turn $\mathrm{n}=\mathrm{n}_{\mathrm{p}} / \mathrm{n}_{\mathrm{s}}$ is obtained in Equation (12).

$$
\mathrm{n}=\mathrm{n}_{\mathrm{p}} / \mathrm{n}_{\mathrm{s}}=\mathrm{G}_{\mathrm{ac}}\left(\mathrm{f}_{\mathrm{sw}}\right) \mathrm{V}_{\mathrm{in}, \max } / \mathrm{V}_{\mathrm{o}}=0.95 \times 400 / 48=7.916
$$

The magnetic core TDK EE-55 with $n=n_{p} / n_{s}=16 / 2=8$ is used to implement transformer $T$. Therefore, the voltage gains at $\mathrm{V}_{\mathrm{in}}=400 \mathrm{~V}$ and $200 \mathrm{~V}$ are calculated in Equations (13) and (14).

$$
\begin{aligned}
& \mathrm{G}_{\mathrm{ac}, \min }=\mathrm{nV}_{\mathrm{o}} / \mathrm{V}_{\mathrm{in}, \max }=8 \times 48 / 400=0.96 . \\
& \mathrm{G}_{\mathrm{ac}, \max }=\mathrm{nV}_{\mathrm{o}} / \mathrm{V}_{\mathrm{in}, \min }=8 \times 48 / 200=1.92 .
\end{aligned}
$$

For high voltage input range, $S_{\text {ac2 }}$ is off. From Equation (4), the ac equivalent load resistance is calculated as.

$$
\mathrm{R}_{\mathrm{e}, \mathrm{ac}}=2 \mathrm{n}^{2} \mathrm{R}_{\mathrm{o}} / \pi^{2}=2 \times 8^{2} \times\left(48^{2} / 500\right) / \pi^{2} \approx 60 \Omega .
$$

The selected resonant inductance $\mathrm{L}_{\mathrm{r}}=7 \mu \mathrm{H}$ so that the magnetizing inductance $\mathrm{L}_{\mathrm{m}}=6 \mathrm{~L}_{\mathrm{r}}=42 \mu \mathrm{H}$. The resonant capacitance $C_{r}$ is calculated in Equation (16). 


$$
\mathrm{C}_{\mathrm{r}}=1 /\left(4 \pi^{2} \mathrm{~L}_{\mathrm{r}} \mathrm{f}_{\mathrm{r}}^{2}\right)=1 /\left(4 \times \pi^{2} \times 7 \times 10^{-6} \times 10^{5} \times 10^{5}\right) \approx 360 \mathrm{nF} .
$$

MOSFETs TK50J60U with $600 \mathrm{~V} / 25 \mathrm{~A}$ ratings are used for power switches $\mathrm{S}_{1}-\mathrm{S}_{4}$ and $\mathrm{S}_{\mathrm{ac} 1}$. IXTP160N075T with $75 \mathrm{~V} / 160 \mathrm{~A}$ ratings is used for power switch $\mathrm{S}_{\mathrm{ac} 2}$. Power diodes MBR40100PT with $100 \mathrm{~V} / 40 \mathrm{~A}$ ratings are adopted for the rectifier diodes $\mathrm{D}_{1}-\mathrm{D}_{4}$. The input and output capacitances are $\mathrm{C}_{\mathrm{in} 1}=\mathrm{C}_{\mathrm{in} 2}=300 \mu \mathrm{F}$ and $\mathrm{C}_{\mathrm{o} 1}=\mathrm{C}_{\mathrm{o} 2}=540 \mu \mathrm{F}$. Two Schmitt voltage comparators are used to control PWM signals of $S_{a c 1}$ and $S_{a c 2}$. The reference voltages of two comparators are designed at $200 \mathrm{~V}$ (between medium and high voltage input regions) and $100 \mathrm{~V}$ (between low and medium voltage input regions). Table 1 shows the specifications of the active and passive components in the studied LLC converter.

\section{Experimental Verification of the Presented Converter}

The hardware circuit of the presented circuit shown in Figure 7 is setup and the circuit specifications are shown in Table 1. The prototype is tested and the measured waveforms are provided to confirm the effectiveness of the presented resonant converter. The PWM signals of active switches at $50 \mathrm{~V}$ input (low voltage input region), $190 \mathrm{~V}$ input (medium voltage input region) and $400 \mathrm{~V}$ input (high voltage input region) and full load are shown in Figure 8a-c respectively. For $\mathrm{V}_{\text {in }}=50 \mathrm{~V}$ input (low voltage range), $S_{a c 1}$ is off, $S_{\text {ac2 }}$ is on and $S_{1}-S_{4}$ are active with switching frequency $\mathrm{f}_{\mathrm{sw}} \approx 65 \mathrm{kHz}$ shown in Figure 8a. For $V_{\text {in }}=190 \mathrm{~V}$ input (medium voltage range), $S_{a c 1}$ and $S_{a c 2}$ are off and only $S_{1}-S_{4}$ are active with switching frequency $\mathrm{f}_{\mathrm{sw}} \approx 102 \mathrm{kHz}$ (Figure $8 \mathrm{~b}$ ). For $\mathrm{V}_{\text {in }}=400 \mathrm{~V}$ input (high voltage range), $S_{\text {ac1 } 1}$ is on and $S_{1}, S_{2}$ and $S_{\text {ac2 }}$ are off. Only $S_{3}$ and $S_{4}$ are active with switching frequency $f_{\mathrm{sw}} \approx 108 \mathrm{kHz}$ shown in Figure 8c. Figures 9 and 10 give the experimental waveforms of input-side and output-side, respectively, at $V_{\text {in }}=50 \mathrm{~V}, 190 \mathrm{~V}$ and $400 \mathrm{~V}$ under full load. For $50 \mathrm{~V}$ input (low voltage range), $S_{\mathrm{ac} 2}$ is on so that $D_{1}$ and $D_{2}$ are active and $D_{3}$ and $D_{4}$ are in the off state as shown in Figure 10a. For $190 \mathrm{~V}$ and $400 \mathrm{~V}$ input conditions, $S_{a c 2}$ is off so that $D_{1}$ and $D_{2}$ are reverse biased and $D_{3}$ and $D_{4}$ are active (Figure 10b,c). From the measured waveforms in Figure 10, the output capacitor voltages $\mathrm{V}_{\mathrm{Co} 1}$ and $\mathrm{V}_{\mathrm{Co} 2}$ are balanced well. Figure 11 gives the PWM signals of power switch $\mathrm{S}_{1}$ or $\mathrm{S}_{3}$ at $50 \mathrm{~V}, 190 \mathrm{~V}$ and $400 \mathrm{~V}$ input under $20 \%$ and $100 \%$ loads. It can observe the ZVS operation of $S_{1}$ and $S_{3}$ is realized for both $20 \%$ and $100 \%$ loads. Figure 12 a shows the input voltage $V_{\text {in }}$ and the gating voltage $v_{S a c 2, g}$ between $V_{\text {in }}=50 \mathrm{~V}$ and $400 \mathrm{~V}$. When $V_{\text {in }} \geq$ or $<100 \mathrm{~V}, S_{\text {ac2 }}$ is off (medium or high voltage range) or on (low voltage range). Figure $12 \mathrm{~b}$ provides the input voltage $V_{\text {in }}$ and $P W M$ voltages $v_{S a c 1}, v_{S 1, g}$ and $v_{S 2, g}$ between $V_{\text {in }}=0 \mathrm{~V}$ and $400 \mathrm{~V}$. When $V_{\text {in }} \geq 200 \mathrm{~V}$ (high voltage input region), $S_{\text {acl }}$ is turned on and $S_{1}$ and $S_{2}$ are turned off. The converter efficiencies for different input voltages and loads are given in Table 2. Under low voltage input region, the $2 \mathrm{n}_{\mathrm{s}}$ winding turns are used on the output-side. Therefore, the higher primary-side current is introduced and the conduction losses on switches and winding turns are increased compared to the $n_{s}$ winding turns used on the output-side under medium and high voltage input regions. Thus, the circuit efficiency at low voltage input region is less than the medium or high voltage input region under the same load. The measured switching frequency at different loads and input conditions are provided in Table 3. On each input voltage region, the higher input voltage results in the higher switching frequency under the same load.

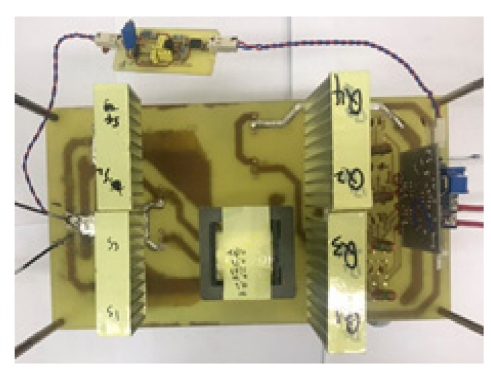

(a)

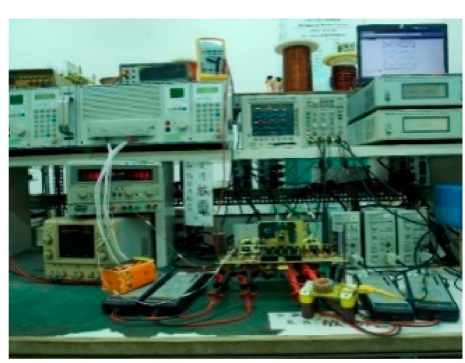

(b)

Figure 7. Presented LLC converter (a) picture of laboratory prototype (b) picture of the experiment setup. 
Table 1. Specifications of the presented converter.

\begin{tabular}{cc}
\hline Items & Parameter \\
\hline Input voltage $\mathrm{V}_{\mathrm{in}}$ & $50 \mathrm{~V}-400 \mathrm{~V}$ \\
\hline Output voltage $\mathrm{V}_{\mathrm{o}}$ & $48 \mathrm{~V}$ \\
\hline Rated power $\mathrm{P}_{\mathrm{o}}$ & $500 \mathrm{~W}$ \\
\hline Resonant frequency $\mathrm{f}_{\mathrm{r}}$ & $100 \mathrm{kHz}$ \\
\hline Input capacitances $\mathrm{C}_{\mathrm{in} 1}, \mathrm{C}_{\mathrm{in} 2}$ & $300 \mu \mathrm{F} / 400 \mathrm{~V}$ \\
\hline Onput capacitances $\mathrm{C}_{\mathrm{o}}, \mathrm{C}_{\mathrm{o} 2}$ & $540 \mu \mathrm{F} / 100 \mathrm{~V}$ \\
\hline resonant capacitance $\mathrm{C}_{\mathrm{r}}$ & $360 \mathrm{nF}$ \\
\hline resonant inductance $\mathrm{L}_{\mathrm{r}}$ & $7 \mu \mathrm{H}$ \\
\hline Power switches $\mathrm{S}_{1-\mathrm{S}_{4}, \mathrm{~S}_{\mathrm{ac} 1}}$ & $\mathrm{TK} 50 \mathrm{~J} 60 \mathrm{U}$ \\
\hline Power switch $\mathrm{S}_{\mathrm{ac} 2}$ & $\mathrm{IXTP} 160 \mathrm{~N} 075 \mathrm{~T}$ \\
\hline Rectifier diodes $\mathrm{D}_{1-} \mathrm{D}_{4}$ & $\mathrm{MBR} 40100 \mathrm{PT}$ \\
\hline Winding turns of $\mathrm{T}: \mathrm{n}_{\mathrm{p}}, \mathrm{n}_{\mathrm{s}}, \mathrm{n}_{\mathrm{s}}$ & $16,2,2$ \\
\hline Magnetizing inductance $\mathrm{L}_{\mathrm{m}}$ & $42 \mu \mathrm{H}$ \\
\hline
\end{tabular}

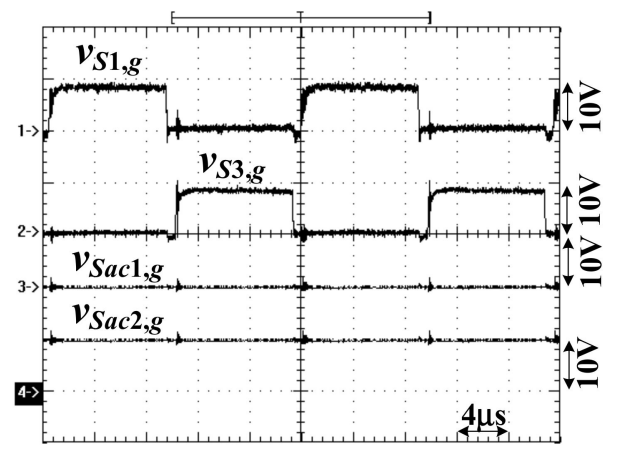

(a)

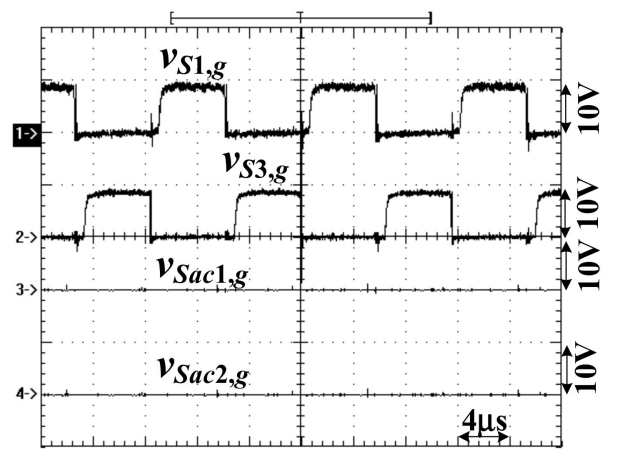

(b)

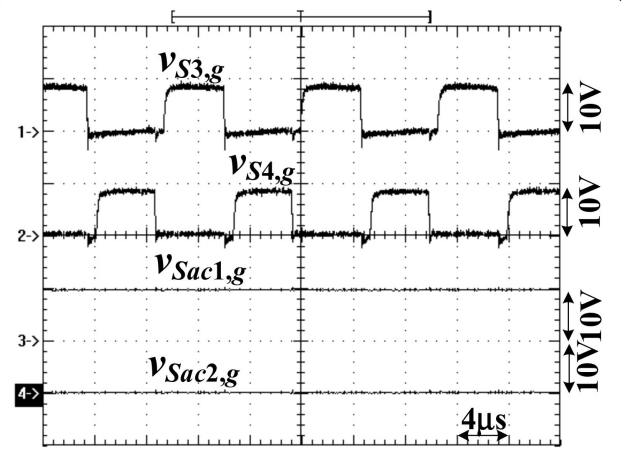

(c)

Figure 8. $P W M$ signals of switches at full load and (a) $V_{\text {in }}=50 \mathrm{~V}$ (low voltage input region) $(\mathbf{b}) \mathrm{V}_{\text {in }}=190 \mathrm{~V}$ (medium voltage input region) (c) $\mathrm{V}_{\text {in }}=400 \mathrm{~V}$ (high voltage input region). 


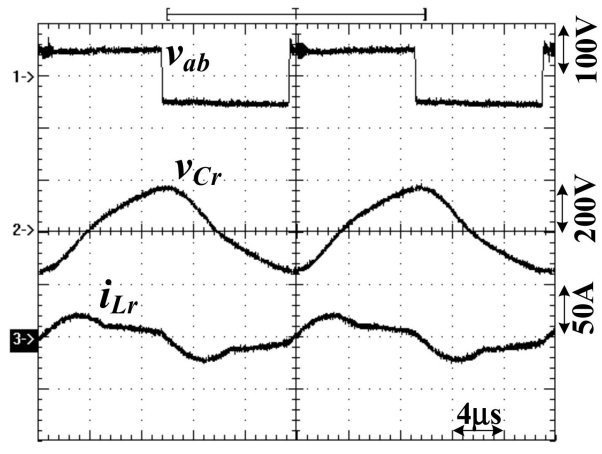

(a)

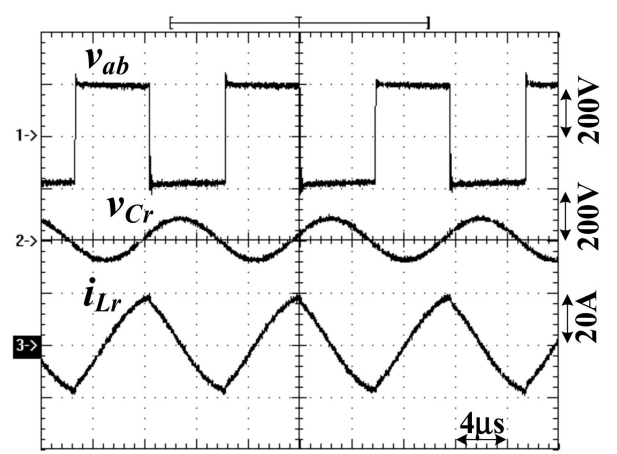

(b)

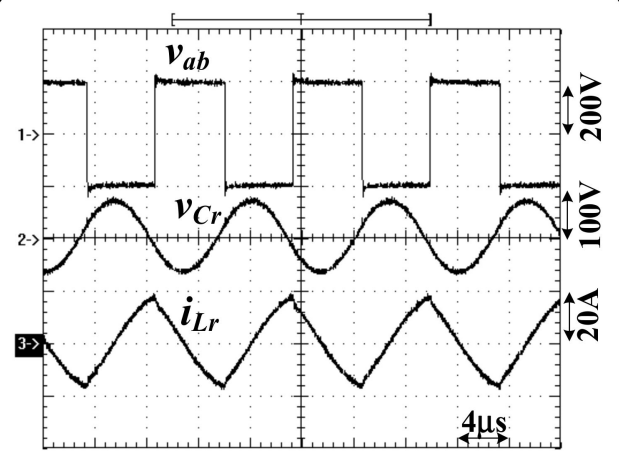

(c)

Figure 9. Input ac voltage $\mathrm{V}_{\mathrm{ab}}$, capacitor voltage $\mathrm{v}_{\mathrm{Cr}}$ and inductor current $\mathrm{i}_{\mathrm{Lr}}$ at full load and (a) $\mathrm{V}_{\text {in }}=50 \mathrm{~V}$ (low voltage input region) (b) $\mathrm{V}_{\text {in }}=190 \mathrm{~V}$ (medium voltage input region) (c) $\mathrm{V}_{\text {in }}=400 \mathrm{~V}$ (high voltage input region).

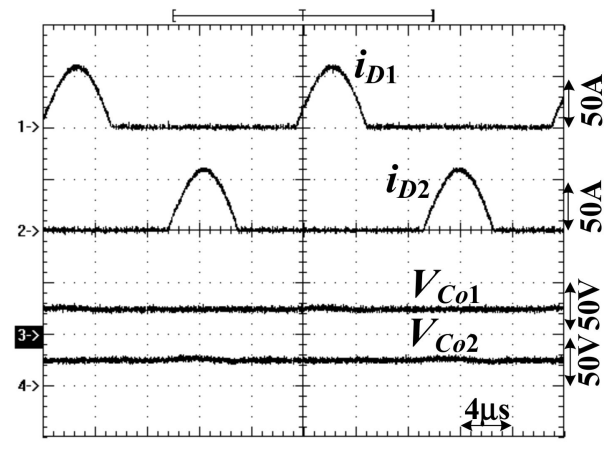

(a)

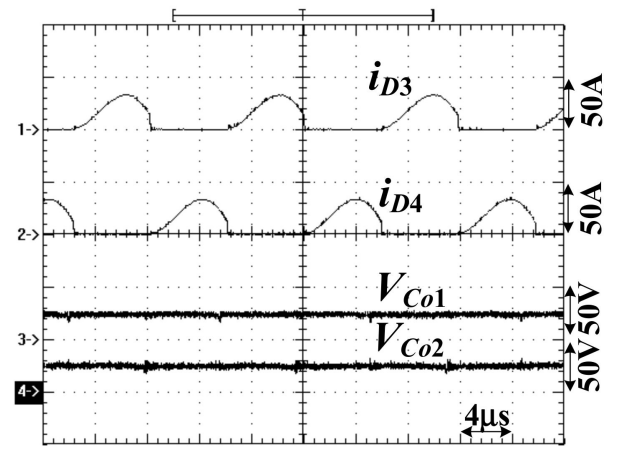

(b)

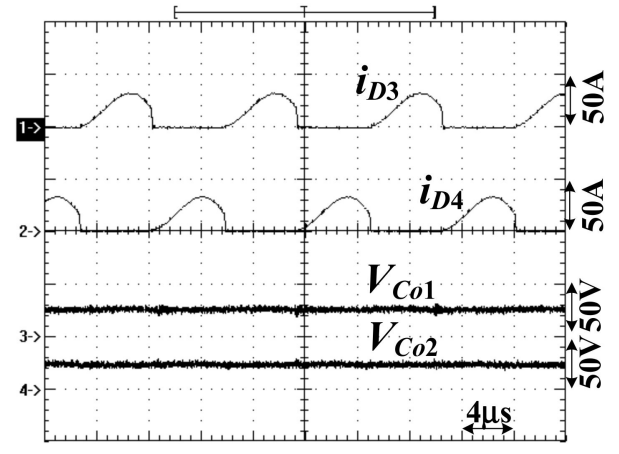

(c)

Figure 10. Output diode currents and capacitor voltages at full load and (a) $V_{\text {in }}=50 \mathrm{~V}$ (low voltage input region) (b) $V_{\text {in }}=190 \mathrm{~V}$ (medium voltage input region) (c) $V_{\text {in }}=400 \mathrm{~V}$ (high voltage input region). 


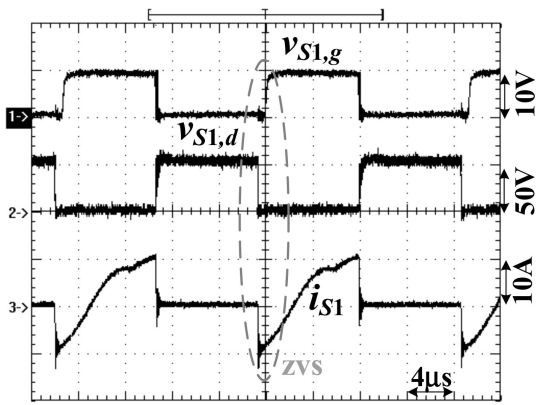

(a)

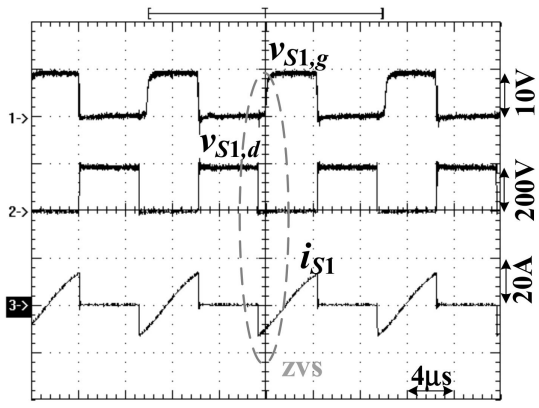

(c)

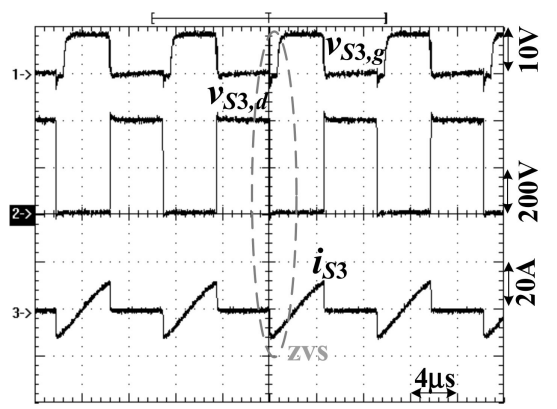

(e)

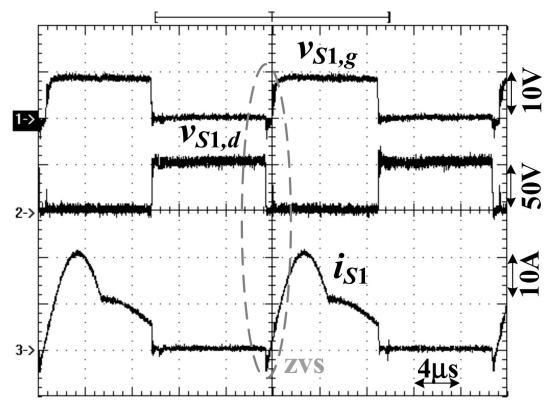

(b)

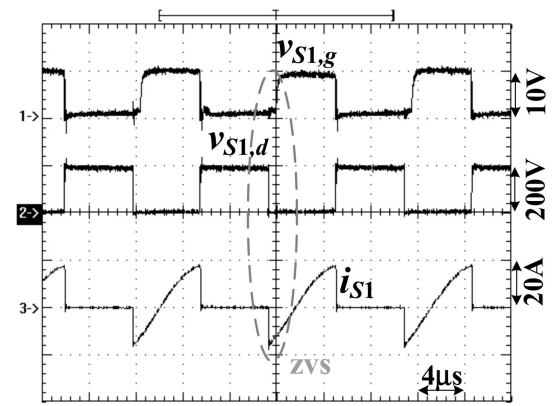

(d)

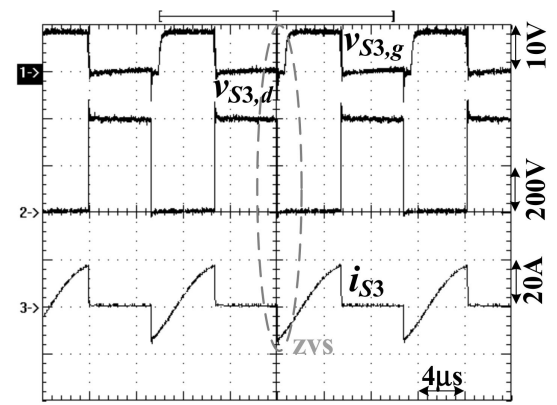

(f)

Figure 11. Measured PWM signals of power switch (a) $S_{1}$ at $V_{\text {in }}=50 \mathrm{~V}$ (low voltage range) and $20 \%$ load (b) $S_{1}$ at $V_{\text {in }}=50 \mathrm{~V}$ (low voltage range) and full load (c) $S_{1}$ at $V_{\text {in }}=190 \mathrm{~V}$ (medium voltage range) and $20 \%$ load (d) $S_{1}$ at $V_{\text {in }}=190 \mathrm{~V}$ (medium voltage range) and full load (e) $S_{3}$ at $V_{\text {in }}=400 \mathrm{~V}$ (high voltage range) and $20 \%$ load (f) $S_{3}$ at $V_{\text {in }}=400 \mathrm{~V}$ (high voltage range) and full load.

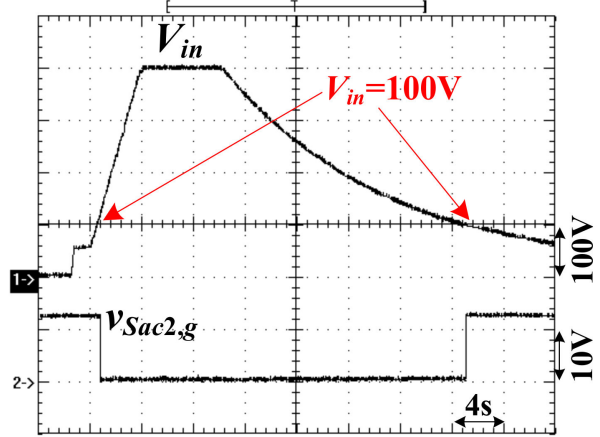

(a)

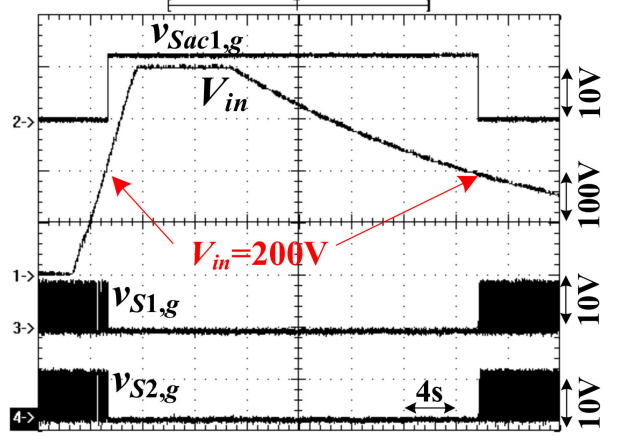

(b)

Figure 12. Measured waveforms (a) $\mathrm{V}_{\text {in }}$ and $\mathrm{v}_{\mathrm{Sac} 2}(\mathbf{b}) \mathrm{V}_{\mathrm{in}}, \mathrm{v}_{\mathrm{Sac} 1}, \mathrm{v}_{\mathrm{S} 1, \mathrm{~g}}$ and $\mathrm{v}_{\mathrm{S} 2, \mathrm{~g}}$. 
Table 2. Measured efficiencies under input voltage and load conditions.

\begin{tabular}{cc}
\hline Input Voltage $\mathrm{V}_{\text {in }}$ & Efficiency \\
\hline $\mathrm{V}_{\text {in }}=50 \mathrm{~V} \& 50 \%$ load (low voltage range) & $88.1 \%$ \\
\hline $\mathrm{V}_{\text {in }}=50 \mathrm{~V} \& 100 \%$ load (low voltage range) & $87.2 \%$ \\
\hline $\mathrm{V}_{\text {in }}=90 \mathrm{~V} \& 50 \%$ load (low voltage range) & $89.7 \%$ \\
\hline $\mathrm{V}_{\text {in }}=90 \mathrm{~V} \& 100 \%$ load (low voltage range) & $88.1 \%$ \\
\hline $\mathrm{V}_{\text {in }}=110 \mathrm{~V} \& 50 \%$ load (medium voltage range) & $89.5 \%$ \\
\hline $\mathrm{V}_{\text {in }}=110 \mathrm{~V} \& 100 \%$ load (medium voltage range) & $88.2 \%$ \\
\hline $\mathrm{V}_{\text {in }}=190 \mathrm{~V} \& 50 \%$ load (medium voltage range) & $91.3 \%$ \\
\hline $\mathrm{V}_{\text {in }}=190 \mathrm{~V} \& 100 \%$ load (medium voltage range) & $90.1 \%$ \\
\hline $\mathrm{V}_{\text {in }}=210 \mathrm{~V} \& 50 \%$ load (high voltage range) & $90.3 \%$ \\
\hline $\mathrm{V}_{\text {in }}=210 \mathrm{~V} \& 100 \%$ load (high voltage range) & $89.6 \%$ \\
\hline $\mathrm{V}_{\text {in }}=400 \mathrm{~V} \& 50 \%$ load (high voltage range) & $92.5 \%$ \\
\hline $\mathrm{V}_{\text {in }}=400 \mathrm{~V} \& 100 \%$ load (high voltage range) & $91.8 \%$ \\
\hline
\end{tabular}

Table 3. Measured switching frequencies under input voltage and load conditions.

\begin{tabular}{|c|c|}
\hline Input Voltage $V_{\text {in }}$ & Switching Frequency $\mathrm{f}_{\mathrm{sw}}(\mathrm{kHz})$ \\
\hline $\mathrm{V}_{\text {in }}=50 \mathrm{~V} \& 50 \%$ load (low voltage range) & 61 \\
\hline $\mathrm{V}_{\mathrm{in}}=50 \mathrm{~V} \& 100 \%$ load (low voltage range) & 52 \\
\hline $\mathrm{V}_{\text {in }}=90 \mathrm{~V} \& 50 \%$ load (low voltage range) & 85 \\
\hline $\mathrm{V}_{\text {in }}=90 \mathrm{~V} \& 100 \%$ load (low voltage range) & 81 \\
\hline $\mathrm{V}_{\text {in }}=110 \mathrm{~V} \& 50 \%$ load (medium voltage range) & 57 \\
\hline $\mathrm{V}_{\text {in }}=110 \mathrm{~V} \& 100 \%$ load (medium voltage range) & 55 \\
\hline $\mathrm{V}_{\mathrm{in}}=190 \mathrm{~V} \& 50 \%$ load (medium voltage range) & 101 \\
\hline $\mathrm{V}_{\mathrm{in}}=190 \mathrm{~V} \& 100 \%$ load (medium voltage range) & 98 \\
\hline $\mathrm{V}_{\text {in }}=210 \mathrm{~V} \& 50 \%$ load (high voltage range) & 57 \\
\hline $\mathrm{V}_{\text {in }}=210 \mathrm{~V} \& 100 \%$ load (high voltage range) & 54 \\
\hline $\mathrm{V}_{\text {in }}=400 \mathrm{~V} \& 50 \%$ load (high voltage range) & 104 \\
\hline $\mathrm{V}_{\text {in }}=400 \mathrm{~V} \& 100 \%$ load (high voltage range) & 97 \\
\hline
\end{tabular}

\section{Conclusions}

A new ZVS LLC converter is presented, analysis and realized to have wide load soft switching and wide voltage input operation. In order to accomplish wide load range of ZVS operation, the LLC resonant tank is used to accomplish ZVS turn-on for all active devices. According to the different input voltage ranges $(50 \mathrm{~V}-400 \mathrm{~V})$, the variable voltage gain is used to regulate load voltage constant. To realize the variable voltage gain which is related to the input voltage range (low, medium or high voltage range), two ac power switches are adopted in order to select half bridge or full bridge resonant circuit with the different turns-ratio of transformer. Thus, the wide range of input voltage operation is realized in the proposed circuit. The studied LLC converter can be applied to wide voltage input variation such as switching power converters with long hold-up time requirement, battery systems or solar panel. Compared to the other wide voltage circuit topologies, the proposed converter has no dc voltage level on the resonant converter [17] and less diode conduction loss [18]. However, more power devices are still needed in the proposed converter to realize 8:1 wide voltage operation. Thus, the cost issue is the main drawback of the studied circuit for industry applications. The presented converter 
has been developed in the laboratory and its effectiveness was validated through experiments by a laboratory prototype circuit.

Author Contributions: B.-R.L. designed and evaluated this project and was also responsible for writing this paper. K.-Y.C. measured the experimental waveforms. All authors have read and agreed to the published version of the manuscript.

Funding: This work was supported by the Ministry of Science and Technology (MOST), Taiwan, under research project MOST 108-2221-E-224-022-MY2.

Conflicts of Interest: The authors declare no conflict of interest.

\section{References}

1. Lin, B.-R. Phase-Shift PWM Converter with Wide Voltage Operation Capability. Electronics 2019, 9, 47. [CrossRef]

2. Lin, B.-R. Analysis of a DC Converter with Low Primary Current Loss and Balance Voltage and Current. Electronics 2019, 8, 439. [CrossRef]

3. Kim, J.; Kim, H.-S.; Baek, J.-W.; Jeong, D.-K. Analysis of Effective Three-Level Neutral Point Clamped Converter System for the Bipolar LVDC Distribution. Electronics 2019, 8, 691. [CrossRef]

4. Steigerwald, R.L. A comparison of half-bridge resonant converter topologies. IEEE Trans. Power Electron. 1988, 3, 174-182. [CrossRef]

5. Lee, J.-B.; Kim, J.-K.; Baek, J.-I.; Moon, G.-W. Resonant Capacitor On/Off Control of Half-Bridge LLC Converter for High-Efficiency Server Power Supply. IEEE Trans. Ind. Electron. 2016, 63, 5410-5415. [CrossRef]

6. Lin, B.-R.; Chu, C.-W. Hybrid full-bridge and LLC converter with wide ZVS range and less output inductance. IET Power Electron. 2016, 9, 377-384. [CrossRef]

7. Zhou, G.; Ruan, X.; Wang, X. Input voltage feed-forward control strategy for cascaded DC/DC coverters with wide input voltage range. In Proceedings of the IEEE IPEMC Conference, Hefei, China, 22-26 May 2016; pp. 603-608.

8. Wang, P.; Zhou, L.; Zhang, Y.; Li, J.; Sumner, M. Input-Parallel Output-Series DC-DC Boost Converter With a Wide Input Voltage Range, For Fuel Cell Vehicles. IEEE Trans. Veh. Technol. 2017, 66, 7771-7781. [CrossRef]

9. Sun, W.; Xing, Y.; Wu, H.; Ding, J. Modified High-Efficiency LLC Converters with Two Split Resonant Branches for Wide Input-Voltage Range Applications. IEEE Trans. Power Electron. 2018, 33, 7867-7879. [CrossRef]

10. Hu, H.; Fang, X.; Chen, F.; Shen, Z.J.; Batarseh, I. A Modified High-Efficiency LLC Converter with Two Transformers for Wide Input-Voltage Range Applications. IEEE Trans. Power Electron. 2013, 28, 1946-1960. [CrossRef]

11. Jeong, Y.; Kim, J.-K.; Lee, J.-B.; Moon, G.-W. An Asymmetric Half-Bridge Resonant Converter Having a Reduced Conduction Loss for DC/DC Power Applications with a Wide Range of Low Input Voltage. IEEE Trans. Power Electron. 2017, 32, 7795-7804. [CrossRef]

12. Yao, Z.; $\mathrm{Xu}, \mathrm{J}$. A three-phase DC-DC converter for low and wide input-voltage range application. In Proceeding of the 2016 IEEE Transportation Electrification Conference and Expo, Asia-Pacific (ITEC Asia-Pacific), Busan, Korea, 1-4 June 2016; pp. 208-213.

13. Lu, J.; Kumar, A.; Afridi, K.K. Step-Down Impedance Control Network Resonant DC-DC Converter Utilizing an Enhanced Phase-Shift Control for Wide-Input-Range Operation. IEEE Trans. Ind. Appl. 2018, 54, 4523-4536. [CrossRef]

14. Wang, X.; Tian, F.; Batarseh, I. High Efficiency Parallel Post Regulator for Wide Range Input DC-DC Converter. IEEE Trans. Power Electron. 2008, 23, 852-858. [CrossRef]

15. Lin, B.-R. Resonant converter with wide input voltage range and input current ripple-free. Electron. Lett. 2018, 54, 1086-1088. [CrossRef]

16. Lin, B.-R. Series resonant converter with auxiliary winding turns: Analysis, design and implementation. Int. J. Electron. 2017, 105, 836-847. [CrossRef]

17. Jovanovic, M.M.; Irving, B.T. On-the-Fly Topology-Morphing Control-Efficiency Optimization Method for LLC Resonant Converters Operating in Wide Input- and/or Output-Voltage Range. IEEE Trans. Power Electron. 2016, 31, 2596-2608. [CrossRef] 
18. Lin, B.-R. Analysis of hybrid converter with wide voltage range operation. J. Power Electron. 2019, 19, 1099-1107. [CrossRef]

Publisher's Note: MDPI stays neutral with regard to jurisdictional claims in published maps and institutional affiliations.

(C) 2020 by the authors. Licensee MDPI, Basel, Switzerland. This article is an open access article distributed under the terms and conditions of the Creative Commons Attribution (CC BY) license (http://creativecommons.org/licenses/by/4.0/). 